La Revista Internacional de la Cruz Roja es el órgano oficial del Comité Internacional de la Cruz Roja. Cuando se publicó por primera vez, el año 1869, se llamaba «Bulletin international des Sociétés de secours aux militaires blessés» y, posteriormente, «Bulletin international des Sociétés de la Croix-Rouge».

Órgano de reflexión, de opinión y de referencia acerca de la misión y de la doctrina del Movimiento Internacional de la Cruz Roja y de la Media Luna Roja, la Revista Internacional de la Cruz Roja es también una publicación especializada en derecho internacional humanitario y en otros aspectos de la acción humanitaria.

Crónica de las actividades internacionales del Movimiento, que conserva memoria de los acontecimientos, la Revista Internacional de la Cruz Roja mantiene una corriente de información y es un vínculo entre los componentes del Movimiento.

La Revista Internacional de la Cruz Roja se publica seis veces al año en cinco idiomas:

en francés: REVUE INTERNATIONALE DE LA CROIX-ROUGE (desde octubre de 1869)

en inglés: INTERNATIONAL REVIEW OF THE RED CROSS (desde abril de 1961)

en español: REVISTA INTERNACIONAL DE LA CRUZ ROJA (desde enero de 1976)

en árabe: البجلة الدولية للصليب الأحمر

(desde mayo-junio de 1988)

en ruso: МЕЖДУНАРОДНЫЙ ЖУРНАЛ КРАСНОГО КРЕСТА

(desde noviembre-diciembre de 1994)

Los artículos de la Revista están disponibles en el servidor Web del CICR, en la sección «publicaciones/periódicos», con las siguientes direcciones:

en inglés (desde 1995): http://www.icrc.org

en francés (desde 1996): http://www.cicr.org

REDACCIÓN: Hans-Peter Gasser, doctor en derecho, redactor jefe

DIRECCIÓN: Revista Internacional de la Cruz Roja

19, avenue de la Paix

CH - 1202 - Ginebra, Suiza

Tel. $(++4122) 7346001$

Fax (++4122) 7332057

Internet: review.gva@icrc.org

SusCRiPCIONES: un año, 30 francos suizos ó 18 dólares EE.UU. cada número, 5 francos suizos

Cuenta de cheques postales: 12 - 5527-6 Ginebra

Cuenta bancaria: 129.986.0 Société de Banque Suisse, Ginebra 


\section{Comité Internacional de la Cruz Roja}

\section{MINAS TERRESTRES ANTIPERSONAL - ¿AMIGO O ENEMIGO?}

\section{Estudio sobre el empleo y la eficacia militares de las minas terrestres antipersonal}

Ginebra, 1996

Este informe ha sido encargado por el CICR, dada la carencia de otros estudios disponibles sobre el empleo y la eficacia de las minas antipersonal en los conflictos. Es fruto de la colaboración entre el CICR, el autor principal, general de brigada retirado e historiador castrense, señor Patrick Blagden, y un grupo de altos mandos del ejército de ocho países, que han contribuido a su realización y apoyan unánimemente las conclusiones. Entre los participantes figuran destacados oficiales del ejército, retirados o en activo, con experiencia personal en el ámbito del empleo bélico de las minas, así como en la conducción de operaciones militares sin tales armas. Tienen experiencia, asimismo, en la guerra convencional, en la respuesta a las insurrecciones y en la prevención del empleo de minas por parte de los insurgentes.

En el estudio se examina la doctrina militar clásica acerca del empleo de minas antipersonal, a la luz de su empleo y su eficacia en 26 conflictos armados ocurridos desde 1940. También se analiza si esas minas se han utilizado de conformidad con la doctrina que justifica su empleo, así como la eficacia de las minas antipersonal en conflictos internos e internacionales o con fines de control de la población. Se estudian, además, la nueva tecnología, que podría cambiar el futuro del empleo bélico de las minas, así como diversas opciones al empleo de minas antipersonal.

El estudio está disponible en español, francés e inglés.

Pueden dirigir sus pedidos a:

Comité Internacional de la Cruz Roja

División de Información Pública

19, Avenue de la Paix, CH-1202 Ginebra

Tel.: (++4122) 730 2422 ó 7302409 - Fax: (++4122) 7348280

Correo electrónico: com_dip.gva@gwn.icrc.org 


\section{FORMULARIO DE SUSCRIPCIÓN}

Deseo suscribirme a la

\section{REVISTA INTERNCIONAL \\ DE LA CRUZ ROJA}

\section{Edición:}

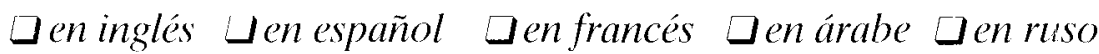

Apellidos

Nombre

Nombre de la Institución

Profesióno cargo

Direccion

País

Remitase a:

REVISTA INTERNCIONAL

DE LA CRUZ ROJA

COMITÉ INTERNACIONAL DE LA CRUZ-ROJA

19, avenue de la Paix $\mathrm{CH}-1202$ Genebra, Suiza

Fax $(++4122) 7332057$

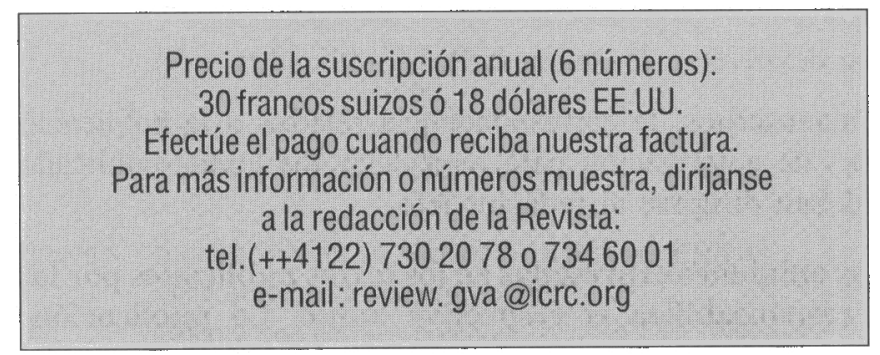

Fecha

Firma 


\section{Presentación de los artículos para la Revista Internacional de la Cruz Roja}

La Revista Internacional de la Cruz Roja invita a sus lectores a enviarle artículos relativos a los diversos aspectos de las actividades del Movimiento Internacional de la Cruz Roja y de la Media Luna Roja o al derecho internacional humanitario. Se tomarán en consideración teniendo en cuenta su valor y el programa temático de la Revista.

Los manuscritos pueden presentarse en francés, inglés, español, árabe o ruso.

Deben estar mecanografiados a doble espacio y no pueden sobrepasar las 20 páginas, es decir, unas 5.000 palabras. El CICR utiliza el programa de tratamiento de texto AmiPro 3.1. Se agradecería el envío de los documentos, preferentemente, en disquete, en AmiPro o en forma ASCII.

Deben numerarse todas las notas del artículo. Se recomienda presentarlas al final del texto, mecanografiadas a doble espacio.

Las referencias bibliográficas se indicarán en el idioma original. Se incluirán los siguientes datos:

a) Para los libros: iniciales y apellidos del autor (en ese orden), título de la obra (en cursiva), lugar de publicación, casa editora y año de publicación (en ese orden), después el número de página (p.) o de páginas (pp.) a las cuales se refiere;

b) Para los artículos: iniciales y apellidos del autor, título del artículo (entre comillas), título del periódico (en cursiva), lugar de publicación, fecha del número, página (p.) o páginas (pp.) a las cuales se refiere.

La redacción se reserva el derecho a modificar los artículos antes de publicarlos.

No se devolverán los manuscritos, publicados o no.

Los manuscritos, la correspondencia relativa a la publicación y las solicitudes de autorización para reproducir los textos publicados en la Revista deben dirigirse al redactor jefe.

De las opiniones expresadas en los textos publicados por la Revista solo se responsabiliza el respectivo autor. La publicación de los mismos no es, pues, una toma de posición del CICR. Dígase lo mismo en cuanto a los textos de la redacción. Solo se pueden atribuir al CICR los que la Institución firma. 


\title{
REVISTA INTERNACIONAL DE LA CRUZ ROJA
}

\author{
$4 \mathrm{CICR}$ \\ PUBUCACIONES

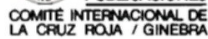 \\ ISSN $0250-569 \mathrm{X}$
}

